\title{
Green TVET Capacity Building in Green Energy Power Generation: Building a Sustainable Engineering Skill Base
}

\author{
YP Chawla ${ }^{1}, \operatorname{RSP}$ Singh $^{2}$ \\ ${ }^{1}$ Joint Electricity Regulatory Commission \& National Joint Secretary - IIPE, National Capital Region, India \\ ${ }^{2}$ School of Vocational Education \& Training (SOVET), IGNOU, New Delhi, India
}

\section{Email address:}

ypchawla@gmail.com (YP Chawla),rspsingh@ignou.ac.in (RSP Singh), rspgsingh@gmail.com (RSP Singh)

\section{To cite this article:}

YP Chawla, RSP Singh. Green TVET Capacity Building in Green Energy Power Generation: Building a Sustainable Engineering Skill Base. International Journal of Vocational Education and Training Research. Vol. 1, No. 3, 2015, pp. 34-41. doi: 10.11648/j.ijvetr.20150103.11

\begin{abstract}
Promoting Energy Efficiency and Green Energy or Renewable Energy are the hottest topics being discussed globally these days, for climate control. Deploying Green Energy / Renewable (GE/RE) and accordingly employment in these areas have gained importance in recent years in India. Green energy employment opportunities continue to grow in various countries. International Renewable Energy Agency (IRENA) estimated that green energy jobs reached 7.7 million in 2014. Largest employers during 2014 for Green Energy Sector were China, Brazil, the United States, India, Germany, Spain and Bangladesh (in that order). And the regional shifts predominantly in the value chain of manufacturing and installation segments are noticed from developed to emerging countries that continue in wind and solar technologies. New Mantra for Indian growth spelt out by the Hon'ble Prime Minister of India is "Skills, Scale and Speed" for getting India back on the economy track. Technical Vocational Education \& Training (TVET) for green energy is termed as GTVET or Green Energy Skills in this paper, as it makes a fit case for building a sustainable engineering skill base in the green economy. GVET has shown Skill Gaps in GE/ RE due to sector's expansion. GTVET spans across various economic sectors through energy saving and urgently needs setting up of the Skill Standards for quantitative measurements of qualitative parameters for the Human Capital Assets required for sector's Capacity Building. The Skill Standards are to act as bench marks for comparing two independent individuals by measuring these, for a useful comparison and for establishing a correlation for further testing the significance of the variations establishing cause and effect relationship for course correction if and as required. The Skill Standards also establish a correlation, between Skilling Institutions, Skilling facilitators and the individuals from diversified geographic regions, countries as well as other stakeholders. Skill Standards Setting Process or the concept of Skill councils is a recent phenomenon in India that got attention after the Skill gaps started getting reflected in the Industry, due to the industries expansion, demographic concerns of aging work force in various countries, for GTVET curriculum remaining unchanged and has not caught up with the dynamic technology changes. This has resulted in expansive "on job learning and self-learning" and poor "Return of Investment in Skilling" for not gaining adequate importance. Skilled manpower is needed for execution of an ambitious GE/RE program envisioned in India. The Skills needed in this sector are broadly covered in this paper. The skilling domain needed in this sector also include Soft Skills within the usual ambit along with the Technical Skills.
\end{abstract}

Keywords: GTVET, Green Skill Gaps, Green Employment, Occupational Standards

\section{Introduction}

International Conference of the Green Jobs Assessment Institutions Network (GAIN) during their recent meeting of 14-16 April 2015 at ILO Hq. reviewed the economic modelling tools and methodological as well as training delivery mechanism on measuring employment and socio-economic effects of shifts to greener economies. This conference was organized under the flag of "Partnership for Action for Green Economy (PAGE)", bringing together the five UN agencies to build national green economy strategies. The Green Economy has become an important aspect of everyone's life, so are green jobs. Technical and Vocational Education and Training with Green emphasis has acquired importance and a new acronym GTVET.

The GTVET includes energy efficiency in every economic activity. The transition to a green economy is a global mega trend affecting skill needs across a diversified range of jobs and sectors. In the labour market, a balance is required between developing generic green skills (e.g. reducing waste, 
improving energy efficiency) and GE specific skills. Today, the green skills are important for almost every job, as are the skills for information and communications technology (ICT). In fact the Solar Energy generation equipment today is in communication with other systems and equipment. Mr. Rónán Haughey during the Bruges Communiqué on enhanced European Cooperation in Vocational Education and Training correctly said green skills for a Hairdresser as are important for a Wind Turbine Maintenance Technician.

The Importance of Green Energy (Solar or Wind) is known and does not need any introduction. With Green Energy taking an important role, the Skills that are required to develop these, maintain the GE/ RE projects and get best returns out of the investments in GE/ RE also are as important. The GTVET in this paper will mainly focus on Solar Jobs.

Dharnai Bihar, India

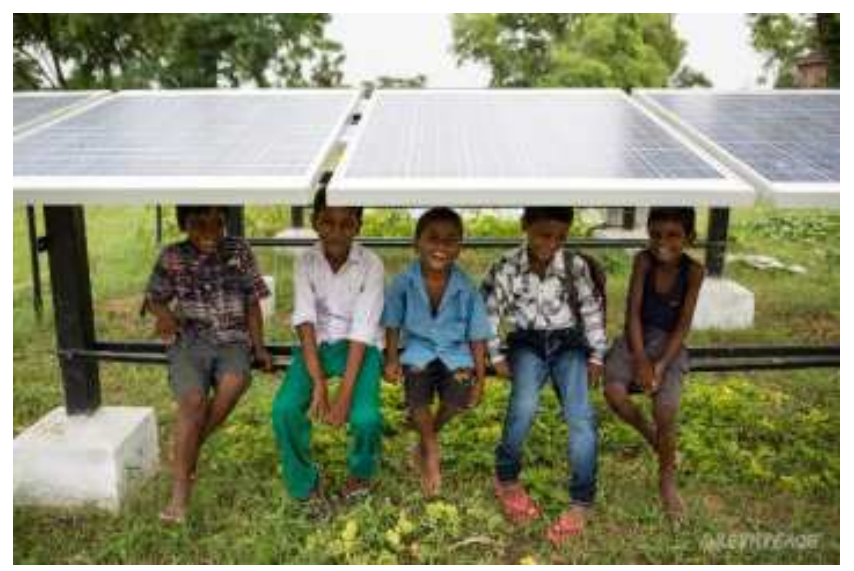

Dharnai village in Bihar, one of India's poorest states, is now lit-up by a Greenpeace India (an NGO with not so good reputation now with GoI) solar-powered micro-grid. It is the first village in India where all aspects of life are powered by solar. The 100 kilowatt $(\mathrm{kW})$ system powers the 450 homes of the 2,400 residents, 50 commercial operations, two schools, a training center and a health care facility. A battery backup ensures the power around the clock.

The Solar Technologies are making the Power reach the remotest part of India and have thus gained importance.

\section{Green TVET - Potential}

India has embarked upon a very ambitious project of going green through an addition of $100 \mathrm{GW}$ of Solar Power Generation capacities with $40 \%$ of the same to be Roof Top grid Connected. Solar Power Generation planned is to be supplemented by $60 \mathrm{GW}$ of wind capacity thus creating an investment opportunity of Indian Rs.630 crores (USD95 Mn.) in Green Energy by 2022. If the new targets of GoI are to be achieved and commitments lived, we need an army of one million youth with GTVET. About $18 \%$ of this number is required for Wind energy and the balance for Solar. During the years' 2011 and 2014 India saw 24,000 Green jobs and now, India has graduated from MW to GW scale, and through Solar projects including Solar Roof Tops more jobs will be created. For a Rooftop solar target of $40 \mathrm{GW}$ by 2022, MNRE has a sub-target of $10 \mathrm{GW}$ for rooftop and other small grid-connected solar projects by 2018. This is expected to further be divided into yearly targets of 2, 4 and $4 \mathrm{GWs}$ (totaling to $10 \mathrm{GWs)} \mathrm{for} \mathrm{the} \mathrm{three} \mathrm{consecutive} \mathrm{years} \mathrm{starting}$ now in 2015. Green Energy Projects journey till 2022 is as depicted in figure 1. The Skills for Solar Power Generation is the focus of the paper. The Solar Power investments are bound to increase steeply to meet the targets specified as shown in figure 1.

\section{Journey till 2022....}

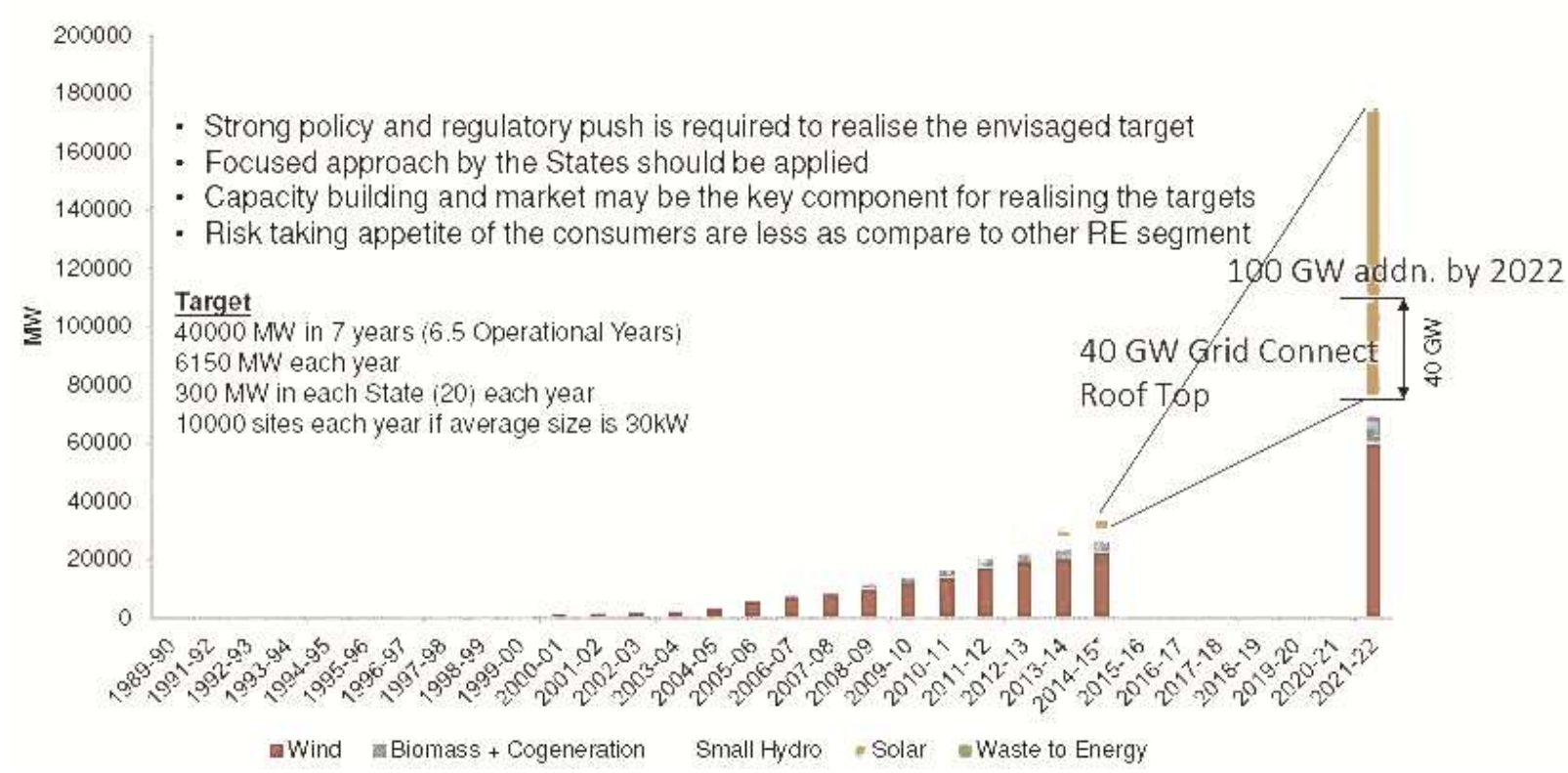

Figure 1. Solar journey till 2022-giz presentation. 


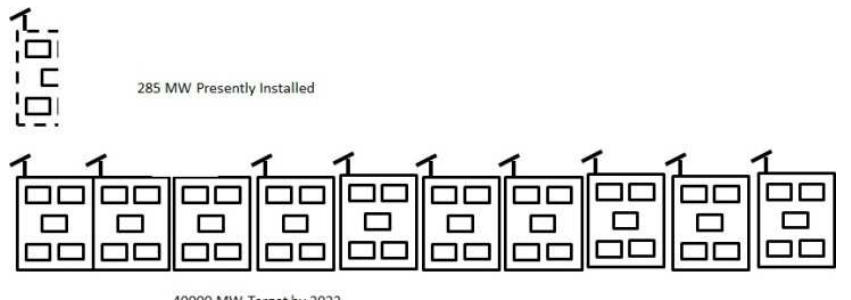

Figure 2. The roof top capacity existing and planned by 2022.

The Solar Roof Top projects take $40 \%$ of the total investments envisaged in Solar Power additions envisaged till 2022 is compared with existing capacity as in figure 2 . These figures are as furnished in a document by Shakti Sustainable Foundation, TERI \& MNRE titled "Reaching the Sun with Roof Top Solar".

The figure 3 also substantiates that there is a market of 124 GW of Solar Project against $100 \mathrm{MW}$ targeted by GoI. Similarly, the Roof Top Solar Power Generation also has a potential more that the target set by GoI.

\begin{tabular}{|c|c|}
\hline & Assesment TERI \\
\hline Market & 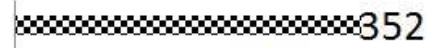 \\
\hline Economic & ||||||||||||||||||||||||||| 210 \\
\hline Technical & 124 \\
\hline
\end{tabular}

\section{Bridge to India Estimate : 57-76 GW Relizable Potentialby 2024}

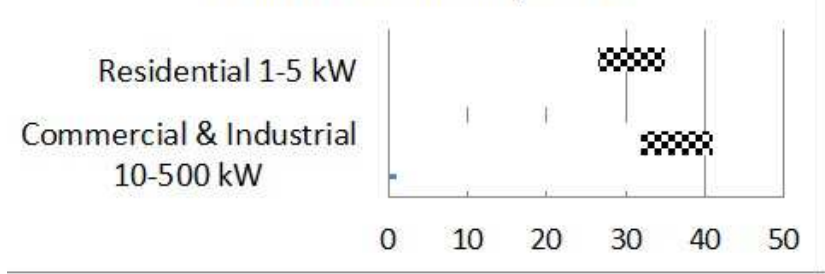

Figure 3. Estimated Solar Generation Potential (Source TERI).

Having set the targets for Green Power Technologies, how are we getting ready with the skilled manpower with GTVET needs a focus. The small size Solar Roof Tops for residential sector will attract small project developers who normally depend on unorganized manpower. Skilling the aspirants and what skills, is a question and worth a debate. GETs / RETs can feed green power through micro grids and reach the remotes and unleash the Potential of Green energy, as an important step for inclusive growth.

\section{Green TVET Skills}

GTVET includes economic, ecological and social aspects, all contributing to a sustainable inclusive development. It is a cross-cutting issue that plays a role in all occupational sectors. GTVET contributes towards a transition to green economies and green societies by providing green competencies in a holistic manner that includes formal, non-formal and informal learning environments. The Green Technologies having a higher sensitivity than other sectors, for GTVET the results directly impact the competitiveness by way of energy availability, improvement in social aspects because of lighted life of mankind, ecology by way of producing green power etc.

\section{Caveats: Solar Energy Targets}

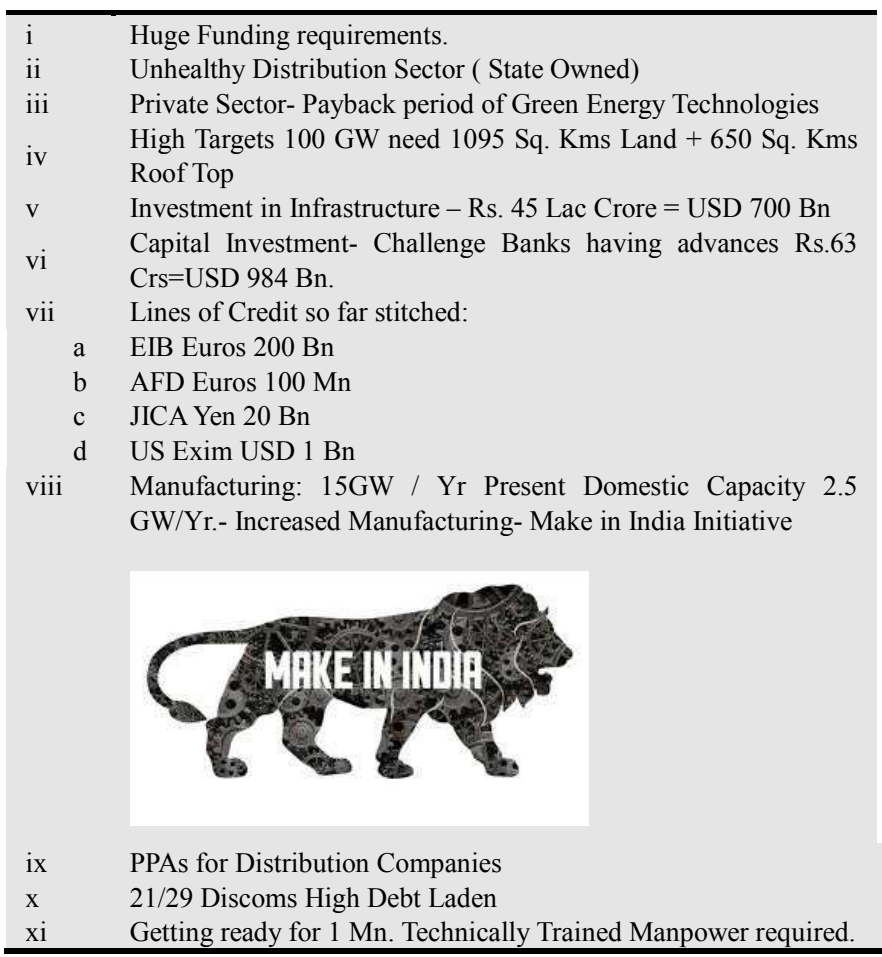

\section{GTVET Model}

\section{Hire and Train or Train and Hire}

Both the models have own advantages \& disadvantages. Hire $\&$ Train offers lesser options of corrections with present Indian labour laws. Train \& Hire gives option of watching the individual during training progress. Also "Train and Hire" model offers readying the manpower for sub-contractors and the unorganized markets.

\section{GTVET Challenges}

GTVET's Training modules are required to specify the skills and knowledge needed to perform effectively in Green Technologies Industry. The training modules normally do not prescribe the delivery mechanism of the training module. The figure 4 Indicates the Career slots from level 01 to 06 (06 being highest) shown vertically and Skill competency levels required from 1 to 5 horizontally on the top row. (5 is highest skill level). Trainers and supervisors keep on developing the learning strategies, to Support the individual learner needs and abilities. Now is the time to achieve the best out of the 
investment made or being made in the Green Energy / Renewable Energy Sector especially Solar Power Generation.

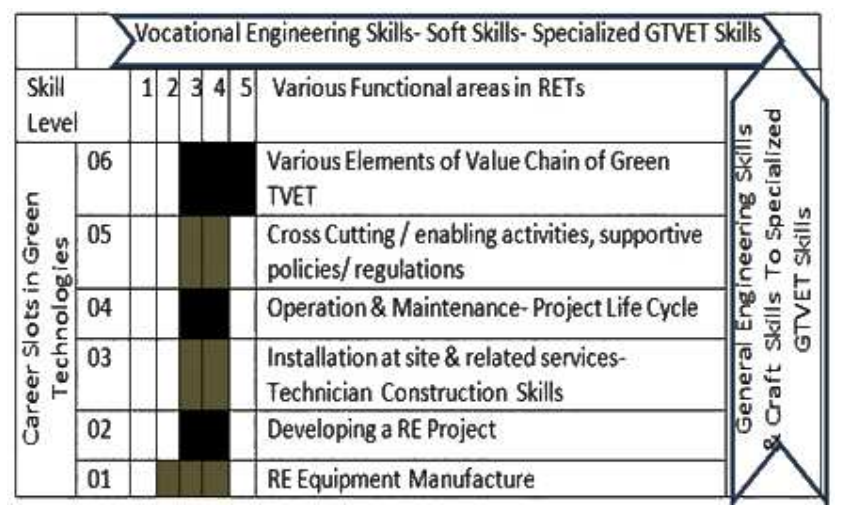

Figure 4. Skill levels for various Functional areas for GTVET

There are so many solar applications installed earlier which now lie abandoned (Solar Street Lights, Solar Pumps, Solar Heaters etc.). This is due to lack of O\&M skills available for these installations. Rehabilitation of these installations could be an economical preposition, for which skilled manpower is required.

The Potential of Green Energy / Renewable Energy Projects in various countries establish the need for setting up a manufacturing base, and the skilling needs for Manufacturing. "Make in India" initiative needs Skill development in manufacturing equipment and systems for these technologies. The manufacturing along with assembling, application of Project development concept, construction of the project at site, its O\&M and then on to the expanding the horizon to various Green Technologies are the important skill requirements. The Skill levels of GTVET needed for various functional areas as in figure $4 \&$ table 1 . Make in India for Green Technologies like solar power generation could succeed, if $R \& D$ is also sufficiently focused in India. The sectoral Skills are needed for R\&D of GETs also.

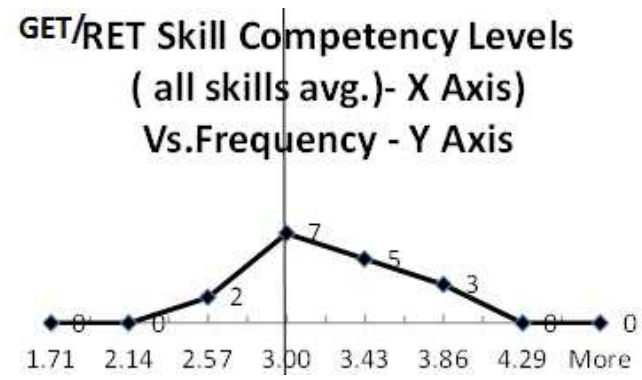

Figure 5. Competency Skill Level - Primary Research.

Table 1. Skill levels for various functional areas ${ }^{l}$.

\begin{tabular}{|c|c|c|c|c|c|c|c|}
\hline & Skills / Function Area & Site Assessment Work & Design for Site & $\begin{array}{l}\text { Coordinating } \\
\text { Resources } \\
\end{array}$ & $\begin{array}{l}\text { System } \\
\text { Installation }\end{array}$ & $\begin{array}{l}\text { System } \\
\text { Maintenance }\end{array}$ & Average \\
\hline & $\mathrm{a}$ & $\mathrm{b}$ & $\mathrm{c}$ & $\mathrm{d}$ & e & $\mathrm{F}$ & $\mathrm{g}$ \\
\hline 1 & Listening & 4 & 3 & 3 & 3 & 3 & 3.2 \\
\hline 2 & Speaking & 4 & 3 & 3 & 3 & 3 & 3.2 \\
\hline 3 & ICT Usage & 4 & 3 & 3 & 3 & 3 & 3.2 \\
\hline 4 & Collect / analyze info & 4 & 4 & 3 & 3 & 4 & 3.6 \\
\hline 5 & Prob. Analyze/ Solving & 4 & 4 & 3 & 4 & 4 & 3.8 \\
\hline 6 & Judgment /Decision & 4 & 4 & 3 & 4 & 3 & 3.6 \\
\hline 7 & Organize \& Plan & 3 & 3 & 3 & 4 & 3 & 3.2 \\
\hline 8 & Social Skills Usage & 3 & 2 & 3 & 3 & 2 & 2.6 \\
\hline 9 & Adaptability & 3 & 3 & 3 & 3 & 3 & 3.0 \\
\hline 10 & Team Work & 2 & 3 & 3 & 4 & 2 & 2.8 \\
\hline 12 & Consensus Building & 2 & 3 & 3 & 3 & 2 & 2.6 \\
\hline 13 & $\begin{array}{l}\text { Enhancing Skill, Self/ } \\
\text { Career Development }\end{array}$ & 2 & 3 & 2 & 3 & 2 & 2.4 \\
\hline 14 & Writing & 3 & 3 & 3 & 2 & 2 & 2.6 \\
\hline 15 & Reading & 3 & 3 & 3 & 3 & 3 & 3.0 \\
\hline 16 & Mathematics & 4 & 4 & 3 & 3 & 3 & 3.4 \\
\hline 17 & Science & 3 & 3 & 2 & 3 & 3 & 2.8 \\
\hline 18 & Average Skill Score & 3.18 & 3.12 & 2.88 & 3.18 & 2.76 & 3.02 \\
\hline 19 & Median Skill Score & 3.00 & 3.00 & 3.00 & 3.00 & 3.00 & 3.00 \\
\hline
\end{tabular}

Higher Skill Score of 4 on a Likert's scale of 1-5 is required in the firm lined boxed areas; Skill Score of around 3 is in the dotted lined boxes. The median of various Skills is at Skill level of 3 on above referred scale and most of the frequencies settle around skill level of 3. GTVET Skills are required above an average score of 2.5 on the Skill Scale of 1-5 and most of these scatter around the median of Skill score level of 3 on the above scale (Figure 5). The average skills that are required for System maintenance and Coordinating resources can be handled by an average skilled worker as per table 1. The Skills required extend to all the above value added components $\&$ systems shown in the top row of Table 1 above. 


\section{Skill Level Required for Various Function Areas in Green Technologies - on a Scale of 1 to $5(5=$ Best $)$}

Skilled workforce fetches a frequency of three (the highest, as in the survey) in the Green Technology value chain as in table 2, reflects its importance over other parameters.

Table 2. GET/ RET Value Chain Requirements \& Skills.

\begin{tabular}{|c|c|c|c|c|}
\hline \multicolumn{5}{|c|}{ GET or RET Value Chain Deployment ${ }^{2}$} \\
\hline $\begin{array}{l}\text { Success } \\
\text { factors - } \\
\text { Right Niche }\end{array}$ & $\begin{array}{l}\text { Proximity to } \\
\text { existing } \\
\text { production }\end{array}$ & $\begin{array}{l}\text { Skilled } \\
\text { workforce }\end{array}$ & $\begin{array}{l}\text { Cluster } \\
\text { quality }\end{array}$ & $\begin{array}{l}\text { value chain } \\
\text { Integration }\end{array}$ \\
\hline Metals & ++ & ++ & + & + \\
\hline Machinery & +++ & +++ & +++ & + \\
\hline $\begin{array}{l}\text { Electrical } \\
\text { devices }\end{array}$ & ++ & ++ & + & ++ \\
\hline $\begin{array}{l}\text { Electronic } \\
\text { parts }\end{array}$ & +++ & +++ & ++ & ++ \\
\hline $\begin{array}{l}\text { Process and } \\
\text { controls }\end{array}$ & ++ & ++ & ++ & + \\
\hline $\begin{array}{l}\text { Construction } \\
\text { preparation }\end{array}$ & + & + & & \\
\hline $\begin{array}{l}\text { Installation, } \\
\text { construction }\end{array}$ & ++ & + & & + \\
\hline $\begin{array}{l}\text { Trade, whole } \\
\text { sale }\end{array}$ & & + & + & ++ \\
\hline Banks & & + & & ++ \\
\hline Insurance & & + & & + \\
\hline $\begin{array}{l}\text { Industrial } \\
\text { services }\end{array}$ & ++ & +++ & ++ & +++ \\
\hline
\end{tabular}

The Solar and Wind technologies are complementary in many aspects of TVET and these GTVETs are to be developed keeping in mind the GE knowledge intensive jobs to support national goals.

The Value Chain Creating jobs through its journey may happen in the following domains of GETs:

Domain 1. R\&D, Manufacture, Project Development

Domain 2. Installation

Domain 3. Operation and Maintenance ( O\&M)

\section{Best Practices Adopted by Various Countries in Above Domains}

The development of Green Energy Technologies may require having Government and the Industry Cooperation in various areas:

a. Policy areas for Investment Promotion

Government has to support the domain $1 \&$ partially in domain 2 above. The balance has to be handled by the Industry. Costa Rica \& Canada have set good policies in this area in above domains.

2 iea-retd.org (Implementing Agreement for Renewable Energy Technology Deployment) Stitching Foundation Renewable Energy Technology Deployment b. Local content requirements, linking the investment to employment and capabilities

This has been best practiced in Ontario, Germany \& Canada, with Private sector taking the front lead by getting in domain listed as 1 above w.r.t. R\&D / manufacture and Project development followed up by the Government to offer the projects for Installation and O\&M (domain 2) thereafter.

c. Developing Productive Clusters / Suppliers Development Programs / Entrepreneurs / Small \& Medium Enterprises

In Green Technologies, the Governments in California, Germany, Ireland, Singapore \& Mexico have taken lead in developing R\&D centers, supporting Manufacturing \& Project Development (domain 1), while the Private Sector has undertaken the development of Installation as well as O\&M teams ( domain 3).

d. Linking Public Research Institutions and the Enterprises

The Governmental mechanism in Germany and Canada provided this support for domains $1 \& 2$ listed above that covers R\&D, Manufacture and Project Development and partially the Installation part. The Private sector took the balance Installation part and the O\&M of GE technologies (domain 2\&3).

e. Advanced Skill Development

Malaysia and Spain have taken lead in advancing the Skill Development in RE by Government leading from front in domains covering R\&D, Manufacture and Project Development and partially the Installation part of domains that are listed at Sl. no $1 \& 2$ above. The Private sector took the balance Installation part and the O\&M of RE technologies.

It is a joint journey of developing Green Technologies by Government \& Industry. The journey begins with adopting the best global practices after studying their relevance to India.

As indicated above, Linking investments in the sector to employment are best practiced in Germany and Canada, while Advanced Skill development is in Malaysia \& Spain and India Skilling should take a note of the same.

\section{Optimizing Operations}

The 2009-2011 - was a period of high risk and high return in respect of Solar Projects in India. Indian developers took advantage of global overcapacity, bankruptcies and raw materials lower costs witnessed. Post 2015, focus is required to focus on O\&M skills as with adequate investment in this regard as manpower costs are about $60-70 \%$ of the O\&M costs. Quick fault restoration spares management, generation management, data acquisition and supervisory control, service level agreement, preventive management etc. are important. IT enabled O\&M systems are helping optimized O\&M. Reducing water consumption maintenance is the challenges of O\&M (benchmark 5000 litters/ day/ MW). Water consumption during Construction is also an important aspect. DC maintenance is more challenging than AC side needs better O\&M attendance and accordingly higher Skills. 


\section{Distributed Renewable Solar Energy Technician Skill Standards-Occupational Skills \& Knowledge with Performance Parameters $^{3}$}

The Solar Energy Technician's Skill Standards / Occupational Skills and knowledge along with performance parameters are broadly listed hereunder:

a. Occupational Skill \& Knowledge: Covering various Skills related to Solar Power Systems are:

i. Electrical systems (AC/DC)

ii. Mechanical systems

iii. Plumbing

iv. Pumps \& theory

v. Energy sources

vi. Blue Prints \& Schematics

vii. Wiring diagrams

b. Performance Parameters: The Skills as at ' $a$ ' above are required to meet the following Industry requirements:

i. Customer Interaction

ii. Performing Site Assessment:

- Equipment location

- Assessment in meeting national \& local codes

- Space Constraints

- Solar Panel tilt angel availability

- System/ load connecting points

- Site accessibility and safety

iii. Working of the Solar Plant is aligned to Company's preliminary design

iv. Calculations of System energy output, Balance of System requirements, developing the component lists drawings / sketches etc.

v. Separately, the Supervisors may be required to meet additional performance requirements that cover:

- Procurement from approved sources

- Inventory Check

- Project Management with scheduling resources

- Approval and obtaining necessary permits

- Stacking Materials as per sequential requirements

- Listing Site Execution Deviations (due to site conditions) from Manufacturers' recommendations

- Devices, Clamps, Screws etc. to be torqued as per Manufacturers' recommendations

- Unsafe site conditions to be reported and corrected

- Any equipment damage during Installation reported

- System output Guarantee

- System Reliability to meet Customer satisfaction rating Technicians Capabilities towards Key Activities to meet performance parameters at sl. ' $b$ ' above:

c. For performance areas of b.i \& b.iv the Technician should

3 Distributed Renewable Solar Energy Technician Skill Standards - USA Feb. 2009 be capable of the following key activities :

- Preliminary Site activities

- Assess Customer's readiness

- Creating Final Drawing (as built)

i. Similarly, the supervisor should be capable of Co-coordinating various resources to meet the requirements as at sl. b.v above.

ii. Understanding of the System analysis, its functions and the requirements are very important for the supervisory level or a senior technician.

iii. Commissioning Capability by a supervisor is a must to achieve System's Guaranteed output as under sl. b.v

iv. System Maintenance capabilities will only be able to achieve customer's satisfaction as at sl. b.v above.

d. The Supporting Conditions as listed hereunder along with the Occupational Skills and Knowledge cannot be ignored.

i. For meeting Performance requirements at Sl. b. the following are needed:

- Language Literacy, Numeracy skills (LLN)

- Use of PC / Laptop,

- Capability to read Blue print, Wiring diagrams, Equipment Manufecturer Manuals, and able to handle various Hand Tools.

ii. The Supervisor, in order to achieve the Performance parameters as at sl. b.v needs to have the worked with above supporting conditions plus Safety equipment \& Knowledge of local codes/ standards of work.

iii. Similarly, the Supervisor, to meet the Performance parameters as at sl. b.v above must understand the following in addition to various other requirements:

- Manufacturers' Manuals

- Handling the Hand / Power tools Safety equipment (personal and job safety)

- Grounding equipment Electrical supplies, rigging equipment Hoisting equipment Work vehicles (including forklift, etc.)

- Materials handling vehicles Blueprints, schematics, wiring diagrams Equipment manufacturer's Manuals, Glues, adhesives, sealants, fasteners, Torque Wrenches

- Safety equipment (personal and job safety)

- Plumbing and pipefitting materials wherever Solar Thermal Systems are involved.

- To provide a system Guarantee the supervisor's supporting condition will be understanding of Electrical / Electronic test equipment, Voltage /Power test equipment to meet the requirements of Performance parameters as at sl. b.v

- The Supervisors and the Senior Technicians are required to be equipped with the understanding of Logging performance data, analyze to see the performance is as committed including periodic maintenance. These are a must to meet the performance parameters as at sl.b.v above.

The Government of India has planned to increase the Renewable Purchase Obligations (RPOs) to $8 \%$ by 2019 and $10.5 \%$ by 2022 (from $3 \%$ by 2022). These RPOs are 
mandatory to meet and are \% of the Electrical Units Sold by Licensee or Purchased by Open access customer and by Captive Power Generator of the conventional power or any other obligated entity.

\section{Conclusions}

An investment of USD 47 bn for Roof Top Solar and a total of USD 100 bn investments have been talked of. $100 \mathrm{GW}$ solar requiring $1 \mathrm{Mn}$. full time jobs, how do we reach this manpower pool with GTVET is a big question? MNRE has come up with arranging skilling of 50,000 people, who will train the balance workforce reaching a total $1 \mathrm{Mn}$. is another question. The Road Map for reaching the above target of providing GTVET is required to be drawn.

Assessing GTVET components as core ingredients in respect of Green Energy Technologies are important as in any other high technology sector, and in principle the GTVET curricula to be competency based, wherein outcome based learning and assessment parameters are required for skill assessment and development. The skill standards are to be developed for Solar Power Generation keeping in view the industry requirements.

\section{Snap Shots of the Paper}

i. Emphasis of the Paper is on Skills which is required for a holistic growth of Solar Power Generation.

ii. This paper by way of secondary research as well as primary research has brought forwards the elements to focus on the GVET curricula.

iii. Way forward suggestions have been provided as under.

\section{Way Forward: For Building a Sustainable Engineering Skill Base of GTVET in Green Energy Generation}

i. You and me being the stakeholders, with your survey response on the web link https:// https://www.surveymonkey.com/r/3H8HXXY the work on establishing Skill Gaps can be initiated. Action: Your good selves

ii. Choosing a road map for developing Green Energy Technologies (Ref Tata Solar- Bridge to India Study) Action: Government / Electricity Regulators.

iii. Aligning Skilling programs of GTVET with 13 ii above, developing Skill Standards, and Validation. Action: PSSE / CBIP/ SESI as Nodal agency, Government, Skilling Institutions, Industry.

iv. Setting up a Skilling institutions for Indian manpower as well as, for providing Skills / accreditation for lesser developed countries abroad which may lead to GE business expansion overseas and competing with other Skill Providers in Europe/ Australia. Action: Govt. Skilling Institutions, Industry

v. The Skilling also to include understanding critical scenarios of Green Energy Technologies Power evacuation based on system demand, with or without a backing of conventional power or micro grids etc. Action: Skilling Institutions.

vi. Extending the concept of investment from CSR to this sector also. While recasting ITIs, the Skill Ministry to explore to tap CSR funding for Solar Sector, along with deployment of funds received towards Skilling under Foreign Contributions Development Fund to be exempted under section 11 of Foreign Contribution Regulation Act 2010 (FCRA), keeping in view large expansion of GETs envisaged. Action: Skilling Ministry.

vii. India needs Vishwamitras (Trainers) for Transforming Indian work force through Transition, like Rama \& Lakshman were trained. These Vishwamitras can bring in excellence in solar plant management needed for enhancing growth of GETs/ RETs. Action: Industry \& Skilling Institutions.

viii. Scale and Speed (in big numbers, with in a time frame) are a must for Skilling India- a must for excelling in the GETs/ RETs; otherwise we will miss the bus to reach the growth levels we are aspiring for under "Make in India" and envisaged growth in the Solar Power Generation sector to let Sun smile on India to make it shine. Till Sector Skill Councils finalize Skill Standards, Industry can come up these standards of their own and can make a contribution in developing these voluntarily Action: Industry \& Skilling Institutions.

ix. Skill development needs-Sharp Focus (identify what is needed in Short term and long Term), Shape (decide on how and where to bring in disrupting technologies), \& Speed growth (projecting and nurturing disrupting innovation). Action: Industry \& Government

$\mathrm{x}$. Indian Population has made Indian Political empowerment achieve a rank of 15 / 142 at World's Economic forum 2014 but ranks poorly in Education attainment 126/142, Economic Participation \& Opportunity Index 134/142. The Govt. of India now in turn is required to empower its people with Skills and Employment, Employment opportunities by facilitating FDI by investor friendly policies, rules, laws, procedures in terms of Labour laws, Land acquisition and approvals to help uplift India's global rank of "ease of doing business" to help India get technologies, Finances for people's empowerment. Action: Govt. of India.

xi. India to quickly bring in a Road Map for Vocational training/GTVET programs matching the aspirations of youth, to be adaptive of the economy, collaborative and be credible (and portable) certifications. Portability to be made available between certificates, diplomas, degrees and also geographical across globe. Action: Government, Vocational Education Institutions.

xii. Before the Skill Gaps are to be closed, the Gap between Vision of Government and the Actualization by various stake holders, Policy Makers' though and Action by various implementing agencies, Strategy developers and Implementers to be filled in and finally India has to move 
on as per the direction and course set in. Action: All Stake holders.

\section{Caveat}

DGE\&T had tried to introduce a program at ITIs but there were no takers. Motivation and job prospects have to be propagated to the job aspirants by CBIP/ MNRE/ Power Sector Skill Council/ Solar Energy Society of India and like organizations appropriately.

\section{References}

[1] Giz Germany, Presentation on Solar Power Energy Journey in India till 2022

[2] Government of India targets of Solar Roof Top till 2022.

[3] The Energy Research Institute (TERI) The Solar Power achievable.

[4] Bridge to India "a study on Targets on Solar Power achievable

\section{Biography}

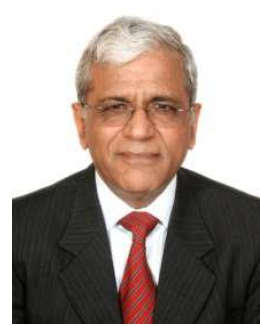

\section{Y P Chawla}

Advisor, Joint Electricity Regulatory Commission, National Jt. Secretary Indian Institution of Plant Engineers (IIPE) BE Tech. \& MBA (Fin), PGDPM \& PGDMM from Delhi University. Export Mgmt. from Oxford. Pursuing PhD. in Skill Gaps in Power Sector, Over 4 decades of Experience in diversified sectors covering Energy including Solar \& other Green / Renewable Energies, (Ex. BHEL), Water Sector, Tyre Manufacturing, setting up Skill Centre, Agriculture, and Infrastructure. Widely travelled in India \& abroad including some Foreign Postings. Because of these postings got opportunities to get a holistic approach of Power Sector. Have written papers on wide range of subjects (available on web) in India”.

[5] YP Chawla \& Dr RSP Singh - GTVET a study.

[6] YP Chawla \& Dr RSP Singh bench marking Indian Capabilities, Distributed Renewable solar energy Technicians' Skill Standards in USA, Feb 2009

[7] iea-retd.org (Implementing Agreement for Renewable Energy Technology Deployment) Stitching Foundation Renewable Energy Technology Deployment.

[8] https://www.academia.edu/14483960/PPT_Green_Power_Te chnologies-_Electricity_Regulations_Market_Policies_and_r elated_Skills- a paper by YP_Chawla

[9] A seminar on Green Technologies https://www.youtube.com/watch?v=cUsmgySSfFo (Seminar 2010)

[10] OECD Green Growth Studies Greener Skills and Jobs by OECD, European Centre for the Development of Vocational Training

[11] Robust assessments for better policies: experts review training package second International Conference of the Green Jobs Assessment Institutions Network (GAIN). 17 April 2015.

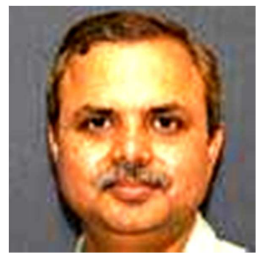

\section{RSP Singh}

An Associate Professor School of Vocational Education\& Training IGNOU -, Has authored papers on various Skill related subjects. Guiding various research projects. Coordinating diversified skilling and educational Programme. PG Certificate \& Diploma in Security and Fire safety, Coordinating Pan India Programme on National rural Livelihood mission, Ministry of Rural Development, Govt. of India; B. Ed. VET (Bachelor of Education in Vocational Education and Training) The contents in this paper are the personal views of the authors and not of the organizations the authors represent. 